\title{
Chapter 19 Separation of hydrogen isotopes by cryogenic distillation
}

Gianluca Valenti, Politecnico di Milano, Via Lambruschini 4A, 20156, Milano (ITALY), +39 022399 3845,

gianluca.valenti@polimi.it 


\section{Abstract}

The hydrogen element exists naturally in the form of three isotopes, sharing the same number of proton and electron, which is equal to one, but not that of neutrons, which ranges from zero to two. In order, these isotopes are: protium, commonly said light hydrogen and indicated with ${ }_{1}^{1} H$ or simply $H$; deuterium, commonly heavy hydrogen indicated with ${ }_{1}^{2} \mathrm{H}$ or $D$; and tritium, ${ }_{1}^{3} \mathrm{H}$ or $T$. Naturally, deuterium abundance is 0.0115 per cent, while tritium is rare and radioactively unstable. Protium, deuterium and tritium form diatomic molecules bonding together, which can be homonuclear, $H_{2}, D_{2}$ and $T_{2}$, or heteronuclear, $H D$, $H T$ and $D T$. Homonuclear molecules can exists in either a ortho modification, $o H_{2}, o D_{2}, o T_{2}$, or a para modification, $p \mathrm{H}_{2}, p D_{2}, p T_{2}$. Hydrogen has the largest isotope effects principally due to the largest differences in the relative mass of its isotopes. Isotope effects are differences in chemical and physical properties arising from differences in the nuclear mass. In particular, lighter hydrogen molecules are characterized by higher vapour pressures than heavier ones; in other words, lighter molecules are more volatile. Among the isotope separation techniques, distillation is adopted in industrial applications because of the advantages of achieving high separation degrees and of processing large quantities of fluids. Distillation is based on the different vapour pressures of the components to be separate and, hence, it requires the coexistence of liquid and vapour phases. Coexistence occurs in the cryogenic range $10-40 \mathrm{~K}$ for molecular hydrogen. The number of cryogenic distillation plants constructed for deuterium and tritium separation is small due to their limited market. One example is the deuterium plant built in Germany in the late 1960s, and another the tritium plant in Canada in late 1980s. Both plants proved the possibility to achieve high purities, exceeding 99.8 per cent, as well as high separation factors. Today, deuterium is employed mostly as constituent of heavy water as neutron moderator for a number of nuclear fission reactors; it is also utilized for the preparation of nuclear weapons or as a non-radioactive tracer in chemical and metabolic reactions. Tritium is used instead as a radioactive tracer in chemistry and biology. Both deuterium and tritium are adopted for the research on the physics of matter and, notably, they have been selected for the future ITER nuclear fusion reactor. 


\section{Keywords}

1. hydrogen isotopes;

2. isotope separation;

3. cryogenic distillation;

4. heavy water;

5. detritiation;

6. fusion reactor;

7. fission reactor;

8. tracer; 


\subsection{Introduction to the Rationale of Separating Hydrogen Isotopes}

The origin of hydrogen isotopes, as after all the origin of everything, dates back to about 13.7 billion years, at the time of the Big Bang. The instant after the bang, the Universe was filled with elementary particles including electrons, whereas protons and neutrons were formed shortly after, but within one second. Few minutes later, protons and neutrons combined into the first nuclei of deuterium and helium, while most protons remained separated as hydrogen nuclei. It took hundreds of thousands of years for electrons and nuclei to unite into the first atoms, which were and have remained mostly hydrogen $[1,2]$. Today, the hydrogen element constitutes 90 per cent of the total atoms or 75 per cent of the total matter preceding by far helium, the second most abundant element. In Space, hydrogen exists predominantly in the atomic and in the ionic state, while partly in the molecular form. On Earth, hydrogen is bonded mostly to other atoms in chemical compounds, such as water and hydrocarbons.

Hydrogen exists naturally as three isotopes, which are called commonly (light) hydrogen $(H)$, deuterium $(D)$ and tritium (T). (The complete terminology is presented in Section 19.2.) They share the same number of proton and electron, which is simply equal to one, but not that of neutrons, which ranges from zero to two respectively. The difference in the neutron number leads to a large relative difference in the atom mass and, ultimately, in physical and chemical properties of the isotopes. Above all, hydrogen and deuterium are stable isotopes, whereas tritium is a radioactive unstable isotope with a relatively long decay time.

In most hydrogen processes, a distinction among its isotopes is unnecessary being the concentration of the light isotope larger by far than that of the heavier isotopes. However, these heavier isotopes have peculiar applications, either civil or military, scientific or industrial, that place a great attention upon them. Deuterium is employed as constituent of the so-called heavy water (water molecules containing mostly one or two deuterium atoms, $\mathrm{HDO}$ and more importantly $\mathrm{D}_{2} \mathrm{O}$, instead of hydrogen atoms, $\mathrm{H}_{2} \mathrm{O}$ ), which is employed in types of nuclear fission reactors for stationary power generation as neutron moderator [3]. It is also employed for the preparation of nuclear weapons or as a non-radioactive tracer in chemical and 
metabolic reactions. Tritium is used instead as a radioactive tracer in chemistry and biology. Both deuterium and tritium are adopted as substrates for the research on the physics of matter and, notably, they have been selected as the best combination for fuelling the future International Thermonuclear Experimental Reactor (widely known as ITER) for power generation [4,5]. Today, the main market of deuterium remains the production of heavy water, while tritium is still a niche product.

In general, the techniques for isotope separation from their mixture are:

1. dependent directly on their diverse atom mass;

2. dependent indirectly on the mass;

3. independent from the mass.

The first kind comprises gravity sedimentation, thermal diffusion, centrifugation, permeation through membranes, electromagnetic deflection, and laser excitation coupled to electric attraction. The second include physical and chemical methods based on the fact that lighter isotopes evaporate at lower temperatures and react at higher rates than heavier ones; in particular, the change in the rate of a chemical reaction upon substitution of one isotope is named kinetic isotope effect. This second class includes distillation and chemical processes. The third one embraces gas chromatography, absorption and adsorption. The alternative to isotope separation is isotope synthetization, which allows obtaining the desired isotope in a pure form by irradiating with neutrons a suitable substrate.

In the case of the hydrogen element, deuterium is produced conventionally by isotopic separation from light hydrogen in an either direct or indirect method. A direct method processes a mixture containing exclusively the hydrogen isotopes, while an indirect method requires a third body. The deuterium direct separation is achieved mostly by way of the distillation of a light hydrogen-deuterium mixture at cryogenic temperatures, while the indirect by way of the deuterium-enrichment of conventional water to heavy water coupled to the electrolysis of the produced heavy water (water is the third body) [6]. Due to its instability and low natural concentration, tritium is produced conventionally by synthetization irradiating 
lithium or heavy water with neutrons. The neutron irradiation of heavy water occurs intrinsically in those nuclear reactors employing heavy water as neutron moderator. In such a case, tritium is produced by the detritiation of the irradiated heavy water by way of a catalytic transfer of tritium from the heavy water to a light hydrogen-deuterium stream coupled to the cryogenic distillation of that stream $[7,8]$. In the future, fusion reactors will also employ a system for the separation of hydrogen isotope based on cryogenic distillation $[9,10]$.

The present chapter focuses on the cryogenic distillation because, on one side, it is a mature process adapt for industrial-size applications and, on the other, it is a direct method for separating the hydrogen isotopes from their mixture in order to "purify" a hydrogen stream into ideally three streams: light hydrogen, deuterium and tritium streams. The following paragraphs illustrate the physical characteristics of the hydrogen isotopes and of the molecules that they form bonding together. They also explain both the basics of the cryogenic distillation as well as of the cryogenic liquefaction. Lastly, they describe two large-scale plants built during the years of the growing interests in the nuclear energy. All paragraphs aim at reporting general concepts while providing a number of references that can be referred to for retrieving specific notions. 


\subsection{Hydrogen Isotopes}

Hydrogen is the most diffuse element in the Universe, one of the most common on Earth and a very vital one for industrial processes and, not less importantly, for life. The following sections are dedicated to the description of hydrogen as an element and as a molecule, highlighting in particular their thermodynamic behaviours that have a direct effect on the design of the liquefaction cycle and the cryogenic distillation. For completeness, a first section reports the general terminology about isotopes.

\subsubsection{General Terminology}

The general terminology about isotopes is provided accordingly to the International Union of Pure and Applied Chemistry (IUPAC) [11]. Terms are listed in a logical sequence rather than in an alphabetical one. Atom. The smallest particle still characterizing a chemical element. It consists of a nucleus of a positive charge ( $Z$ is the proton number and $e$ the elementary charge) carrying almost all its mass (more than 99.9\%) and Z electrons determining its size.

Element or chemical element. A species of atoms; all atoms with the same number of protons in the atomic nucleus.

Nuclide. Species of atom, characterized by its mass number, atomic number and nuclear energy state, provided that the mean life in that state is long enough to be observable.

Isotopes. Nuclides having same atomic number but different mass number.

Atomic number or proton number $(Z)$. The number of protons in the atomic nucleus.

Mass number or nucleon number $(A)$. Total number of heavy particles (protons and neutrons jointly called nucleons) in the atomic nucleus.

Elementary charge or proton charge (e). Electromagnetic fundamental physical constant equal to the charge of a proton and used as atomic unit of charge, equal to $1.602176487(40) \cdot 10^{-19} \mathrm{C}$.

Isotope exchange. A chemical reaction in which the reactant and product chemical species are chemically identical but have different isotopic composition.

Nuclear decay. A spontaneous nuclear transformation. 
Nuclear transformation. The change of one nuclide into another with a different proton number or nucleon number.

Half-life. Time needed for the concentration of an entity to decrease to one half of its original value. Additionally, an isotope can be stable or unstable, whether it is subjected to a nuclear decay or not. Moreover, they can be natural, whether occurring naturally, as opposed to synthetic. In general, natural isotopes may be either stable or unstable, while synthetic isotopes are typically unstable.

\subsubsection{Hydrogen Element}

Hydrogen is the first element in the periodic table having the simplest atomic structure of all the elements; its nucleus comprises a single proton and it has only one outer electron. There are three isotopes of hydrogen occurring naturally and having none, one or two neutrons in the nucleus respectively [12-14]:

- $\quad{ }_{1}^{1} H$, also called protium, ${ }^{\mathrm{a}}$ light hydrogen, ordinary hydrogen, hydrogen-1 or $H$;

- $\quad{ }_{1}^{2} H$, also deuterium, heavy hydrogen, hydrogen-2 or $D$;

- $\quad{ }_{1}^{3} H$, also tritium, super heavy hydrogen, heavy-heavy hydrogen, hydrogen-3 or $T$. In 1988, Bunnett and Jones [15] established the nomenclature for hydrogen atoms, ions, and groups in agreement with the IUPAC rules. The general name of the atom is thus hydrogen, while the specific names for the isotopes are protium, deuterium and tritium. Accordingly, the cations, positively charged, are proton, deuteron and triton, while the anions protide, deuteride, and tritide, respectively (these latter ones will be recalled in Section 19.2.3). Figure 19.1 visualizes schematically the structure of the three isotopes of hydrogen. On top of the isotopes occurring naturally, even heavier ones can be synthetized in laboratory: Korsheninnikov et al. [16] proved the possibility of manufacturing isotopes up to ${ }_{1}^{7} H$ (hydrogen-7).

Historically, Birge and Menzel suggested the existence of the two stable hydrogen isotopes in mid-1931, while Urey, Brickwedde and Menzel proved it in late 1931. Urey et al. proposed the special names of protium and deuterium, which derive from the ancient Greek words first and second. Rutherford, Oliphant

\footnotetext{
a For the generic element $X$, the nomenclature ${ }_{Z}^{A} X$ indicates the mass number $A$ and the atomic number $Z$, thus identifying univocally the specific isotope of $X$.
} 
and Harteck observed an unstable isotope in 1934 and gave it the name tritium, meaning third. In recent years, Berglund and Wieser reported - on behalf of the Commission on Isotopic Abundances and Atomic Weights (CIAAW) of IUPAC - the table of isotopic compositions of the elements. According to the table, the representative isotopic composition of protium is $0.999885(70)$, while that of deuterium is $0.000115(70) ;$ their observed range of natural variations are 0.999816 to 0.999974 and 0.000026 to 0.000184 , respectively [17]. In contrast, tritium occurs naturally only in traces beings formed by the interaction of cosmic rays with atmospheric gases; its atmospheric content is estimated to be 1 tritium atom every $10^{18}$ protium atoms [12].

Differences in chemical and physical properties arising from differences in the nuclear mass of an element are called isotope effects. Among all the elements, hydrogen has the largest isotope effects principally due to the largest differences in the relative mass of the isotopes. (This fact justifies the use of distinctive names for hydrogen isotopes in contrast to all other elements that have no separate names for their isotopes.) In the case of hydrogen, the chemical properties of protium, deuterium, and tritium are essentially equal, exception made in matters such as equilibrium constants and reaction rates. Moreover, protium and deuterium are stable isotopes, whereas tritium is radioactive unstable isotope, subjected to a nuclear decay with a half-life of 12.4 years. Table 19.1 shows the main atomic properties of the three isotopes [12].

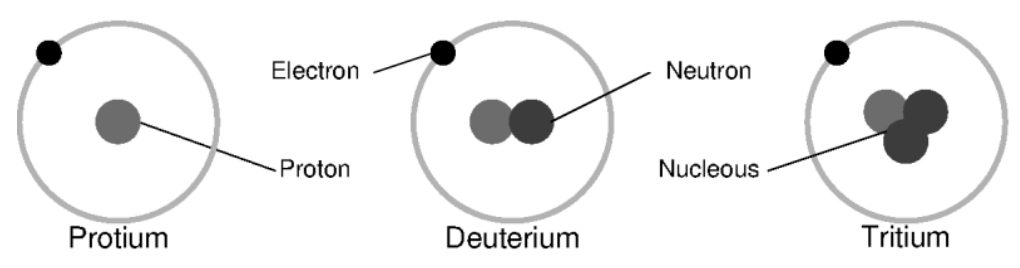

Figure 19.1. Schematic illustration of the three isotopes of hydrogen element that occur naturally: protium (or ordinary hydrogen, which is the most abundant by far), deuterium (heavy hydrogen) and tritium.

\footnotetext{
b The representative isotopic composition is, according to CIAAW, "the isotopic composition of chemicals and/or natural materials that are likely to be encountered in the laboratory. [...] for elements with known isotope-abundance variations, they may not necessarily correspond to the best measurements."
} 
Table 19.1. Atomic properties of the three isotopes of hydrogen that occur naturally: protium, deuterium and tritium (extracted from [12]).

\begin{tabular}{llccc}
\hline Properties & Units & hProtium, ${ }_{\mathbf{1}}^{\mathbf{1}} \boldsymbol{H}$ & Deuterium, ${ }_{\mathbf{1}}^{\mathbf{2}} \boldsymbol{H}$ & Tritium, ${ }_{\mathbf{1}}^{\mathbf{H}} \boldsymbol{H}$ \\
\hline \hline Relative atomic mass & a.m.u. & 1.007825 & 2.014102 & 3.016049 \\
\hline Nuclear spin quantum number & - & $1 / 2$ & 1 & $1 / 2$ \\
\hline Radioactive stability & - & Stable & Stable & Unstable \\
\hline
\end{tabular}




\subsubsection{Hydrogen Molecules: Isotopic Forms and Ortho/Para Modifications}

Protium, deuterium and tritium can combine and form diatomic molecules. If the molecule is made by two atoms of the same isotope, as for the case of $\mathrm{H}_{2}, \mathrm{D}_{2}$ and $\mathrm{T}_{2}$, it is said homonuclear diatomic molecule (or also isotopic diatomic molecules); on the contrary, $H D, H T$ and $D T$, heteronuclear diatomic molecule. Thus, there are six isotopic forms:

- $\mathrm{H}_{2}$, diprotium (generally said molecular hydrogen or simply hydrogen),

- $D_{2}$, dideuterium (generally molecular deuterium or simply deuterium),

- $T_{2}$, ditritium (molecular tritium or tritium),

- HD, hydrogen deuteride,

- HT, hydrogen tritide,

- $\quad$ DT, deuterium tritide.

Being deuterium scarcely abundant and tritium rare, molecular hydrogen is approximated to be solely $H_{2}$ for most industrial applications. Nevertheless, this approximation is not applicable for peculiar applications, like the isotope separation covered in this chapter. Figure 19.2 visualizes schematically the structure of the six isotopic forms of diatomic molecular hydrogen.

Molecular hydrogen was observed accidentally for the first time by Theophrastus von Hohenheim, also known as Paracelsus, who noted that the attack of strong acids against metals generated a flammable gas. Other chemists and physicists repeated his experience, including Robert Boyle who described the properties of this flammable gas in 1671 . The credit of the discovery that the generated gas was made of a new element is attributed commonly to Henry Cavendish because he was able to isolate it and measure its relevant properties in 1776. Shortly later, in 1783, Antoine Lavoisier gave the new element the name hydrogen after he discovered, in collaboration with Pierre-Simon Laplace, that burning it in air produced water. Etymologically, hydrogen means forming, genes, water, hydro, both words belonging to ancient Greek. Lastly, peculiar properties of the homonuclear hydrogen molecules, as opposed to the 
heteronuclear ones, were discovered spectroscopically and interpreted via quantum mechanics by Heisenberg in 1927.

Molecular hydrogen, as any other substance, can be described by Statistical thermodynamics, the branch of Physics that studies the matter combining the probability theory and the quantum mechanics with a microscopic mechanical model of the constituents of the matter itself. Its aim is predicting the properties that are measurable at the macroscopic level based on the microscopic behaviour of the measured substance [18].

According to the Statistical thermodynamic theory, for the homonuclear diatomic molecules, such as $\mathrm{H}_{2}$, $D_{2}$ and $T_{2}$, there is a division of the quantized rotational energy levels of their nuclear spins into two groups that are referred to as the ortho and the para modifications. One series is composed of the even numbered and the other of the odd numbered levels. For the case of $\mathrm{H}_{2}$ and $T_{2}$, ortho modification is composed of odd numbered, while para of even ones; on the contrary, for the case of $D_{2}$, the ortho modification is composed of even numbered, while para of odd ones (the motivation is provided later in this section). Thus, there are six ortho/para modifications:

- $\mathrm{OH}_{2}$, orthodiprotium (generally said orthohydrogen),

- $\mathrm{pH}_{2}$, paradiprotium (generally parahydrogen),

- $o D_{2}$, orthodideuterium (or simply orthodeuterium),

- $p D_{2}$, paradideuterium (simply paradeuterium),

- $o T_{2}$, orthoditritium (orthotritium),

- $p T_{2}$, paraditritium (paratriutium).

In simpler words, the distinction between the two modifications of homonuclear diatomic molecules is the relative spin of the two nuclei. Figure 19.3 visualizes schematically the structure of the six ortho/para modifications of homonuclear diatomic hydrogen. 
In few words, molecular hydrogen exists in various isotopic forms and ortho/para modifications, yielding a general mixture of nine molecules: $o H_{2}, p H_{2}, o D_{2}, p D_{2}, o T_{2}, p T_{2}, H D, H T$, and $D T$.

The relative composition between ortho and para modifications of homonuclear diatomic molecules varies with temperature. The equilibrium composition at room temperature is named the normal composition, and the abundant component is indicated as the ortho modification. In addition, the equilibrium composition at any temperature is named simply equilibrium composition and, in particular, at ambient temperature, normal and equilibrium compositions are the same mixture. Thus, there are six important compositions:

- $n-H_{2}$, normal-composition diprotium (generally said normal-hydrogen),

- $e-H_{2}$, equilibrium-composition diprotium (generally equilibrium-hydrogen),

- $n$ - $D_{2}$, normal-composition dideuterium (normal-deuterium),

- $e$ - $D_{2}$, equilibrium-composition dideuterium (equilibrium-deuterium),

- $n-T_{2}$, normal-composition ditritium (normal-tritium),

- $e-T_{2}$, equilibrium-composition ditritium (equilibrium-tritium).

Figure 19.4 visualizes how the ortho-para composition at equilibrium varies for $H_{2}, D_{2}$ and $T_{2}$ in the temperature range from 0 to $300 \mathrm{~K}$.

In 1948, Woolley et al. [19] reported the computation of thermal data for $H_{2}, H D$ and $D_{2}$ in solid, liquid and gaseous states, including the distinctive properties of ortho and para modifications of $\mathrm{H}_{2}$ and $\mathrm{D}_{2}$. Hoge and Arnold [20] presented in 1951 the measured vapour pressures of $e-H_{2}, H D$ and $e-D_{2}$ in the wide range from near their triples points up to their critical points. Moreover, they also provided the dew-point pressures of several binary mixtures, indicating a difference of about 3 per cent above those predicted by the law of ideal solutions, also known as the Raoults' Law. In other words, the ideal solution model is appropriate for the $H_{2}, H D$ and $D_{2}$ mixture for engineering purposes. In the same year, the authors [21] reported the measurements of their critical temperatures, pressures and volumes. Given the growing role 
of hydrogen as research tool in chemistry, physics, biology and nuclear engineering, Haar et al. [22] recounted in 1961 the results of a decade-long research on the isotope effects in hydrogen compounds undertaken by the United States National Bureau of Standards (NBS, now National Institute of Standards and Technology - NIST). The research covered data of state, reaction kinetics, thermodynamic functions, and a variety of other physico-chemical phenomena of diatomic hydrides, deuterides and tritides. These molecules are diatomic compounds comprising protide, deuteride, and tritide, and eventually another element. Roder et al. [23] completed a survey, as of the year 1972, about volumetric, thermodynamic, thermal, transport, electrical and mechanical properties of all hydrogen isotopes forms and ortho/para modifications below their critical points. Shortly later, in 1981, McCarty et al. [24] replicated the survey focusing mainly on the light isotope of hydrogen. Today, the studies by Jacobsen, Leachman, Richardson, Lemmon and colleagues are likely the most advanced analyses of thermodynamic and thermophysical properties of hydrogen in all isotopic forms and ortho/para modifications [25-29]. All these cited publications are still of large use for the investigation about the properties of the hydrogen. As a rule, isotopic forms and ortho/para modifications yield large relative differences in the thermodynamic properties of the diverse molecules at same temperature and pressure only within the cryogenic region.

The ortho/para conversion reaction from the ortho to the para modification, as well as the reversed reaction, is a very slow reaction, unless it is promoted catalytically. This kind of reactions describes the equilibrium among the ortho/para modification as follows:

- $\mathrm{oH}_{2} \rightleftarrows p \mathrm{H}_{2}$

- $o D_{2} \rightleftarrows p D_{2}$

- $\quad o T_{2} \rightleftarrows p T_{2}$

The conversion reactions are exothermic as temperature decreases and characterized by values of the enthalpy of conversion of similar magnitude to those of the enthalpy of evaporation. Therefore, the analysis of ortho-para composition and the catalytic promotion of their conversion is of utmost importance for the 
storage of the liquefied hydrogen, which would evaporate otherwise in the tank during the slow conversion from one modification to the other.

Similarly to the conversion reaction, also the isotope exchange (Section 19.2.1) between any two hydrogen isotopes is a slow reaction, unless promoted catalytically. This kind of reactions describes the equilibrium among heteronuclear and homonuclear hydrogen molecules as follows:

- $2 H D \rightleftarrows H_{2}+D_{2}$

- $2 H T \rightleftarrows H_{2}+T_{2}$

- $2 D T \rightleftarrows D_{2}+T_{2}$

The isotope exchanges shift rightward, that is the equilibrium shifts from heteronuclear molecules to homonuclear molecules, at lower temperatures. This characteristic is exploited favourably in the distillation processes to concentrate the isotopes in their homonuclear diatomic molecules.

As it will be motivated in Section 19.3, the working principle of distillation is the difference among vapour pressures of the components to be separated. Table 19.2 reports the fixed points, which are the triple and critical points, for the diatomic molecules of interest, while Figure 19.5 visualizes their vapour pressures between the fixed points. As a general rule, lighter hydrogen molecules are characterized by higher vapour pressures with respect to heavier molecules at the same temperature. In other words, lighter molecules are more volatile than heavier ones. 


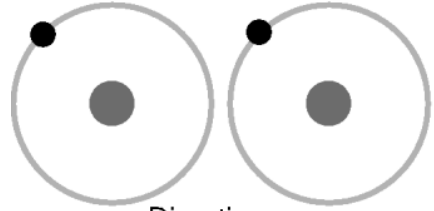

Diprotium (hydrogen)

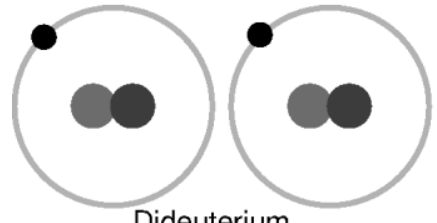

Dideuterium (deuterium)

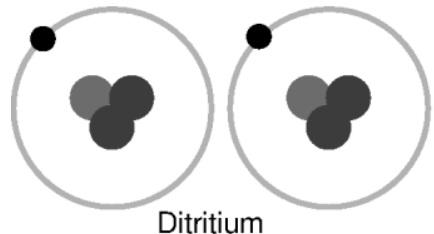

(tritium)

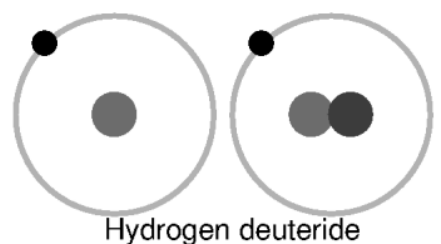

Hydrogen deuteride

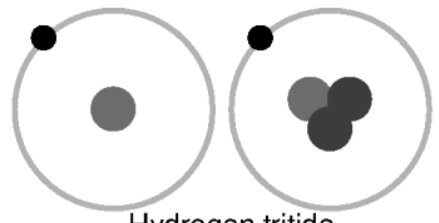

Hydrogen tritide

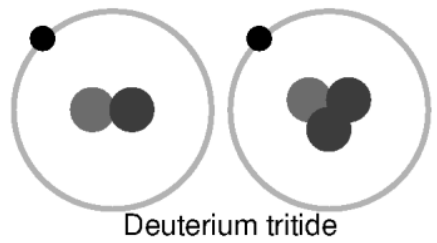

Figure 19.2. Schematic illustration of the six isotopic forms of the diatomic molecules of hydrogen that occur naturally: diprotium (or simply hydrogen, which is the most abundant by far), dideuterium (or hydrogen), ditritium (or tritium), hydrogen deuteride, hydrogen tritide, and deuterium tritide.
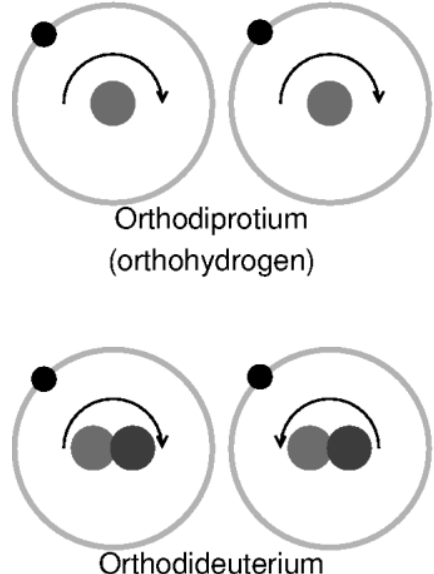

(orthodeuterium)

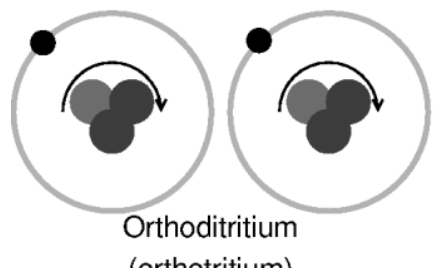

(orthotritium)
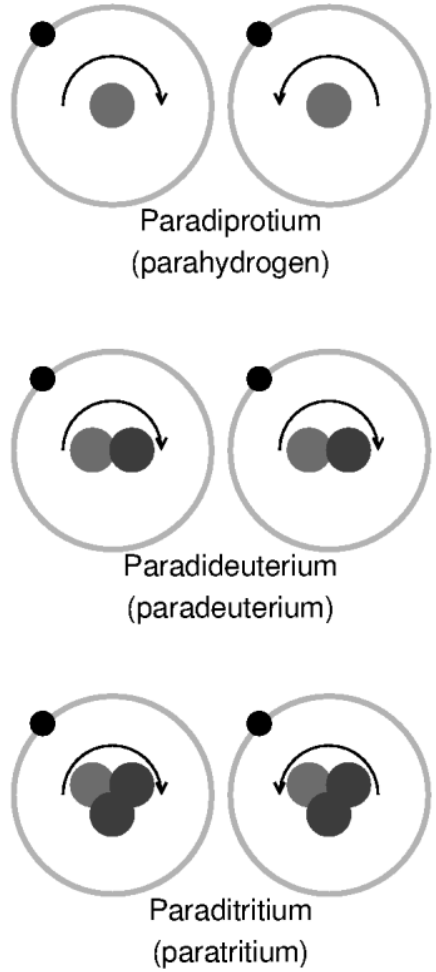

Figure 19.3. Schematic illustration of the six ortho/para modifications of the homonuclear diatomic hydrogen that occur naturally showing the relative spin of the two nuclei: ortho- and paradiprotium (or simply ortho- and parahydrogen, which are the most abundant by far), ortho- and paradideuterium (or ortho- and paradeuterium), ortho- and paraditritium (or ortho- and paratritium). 


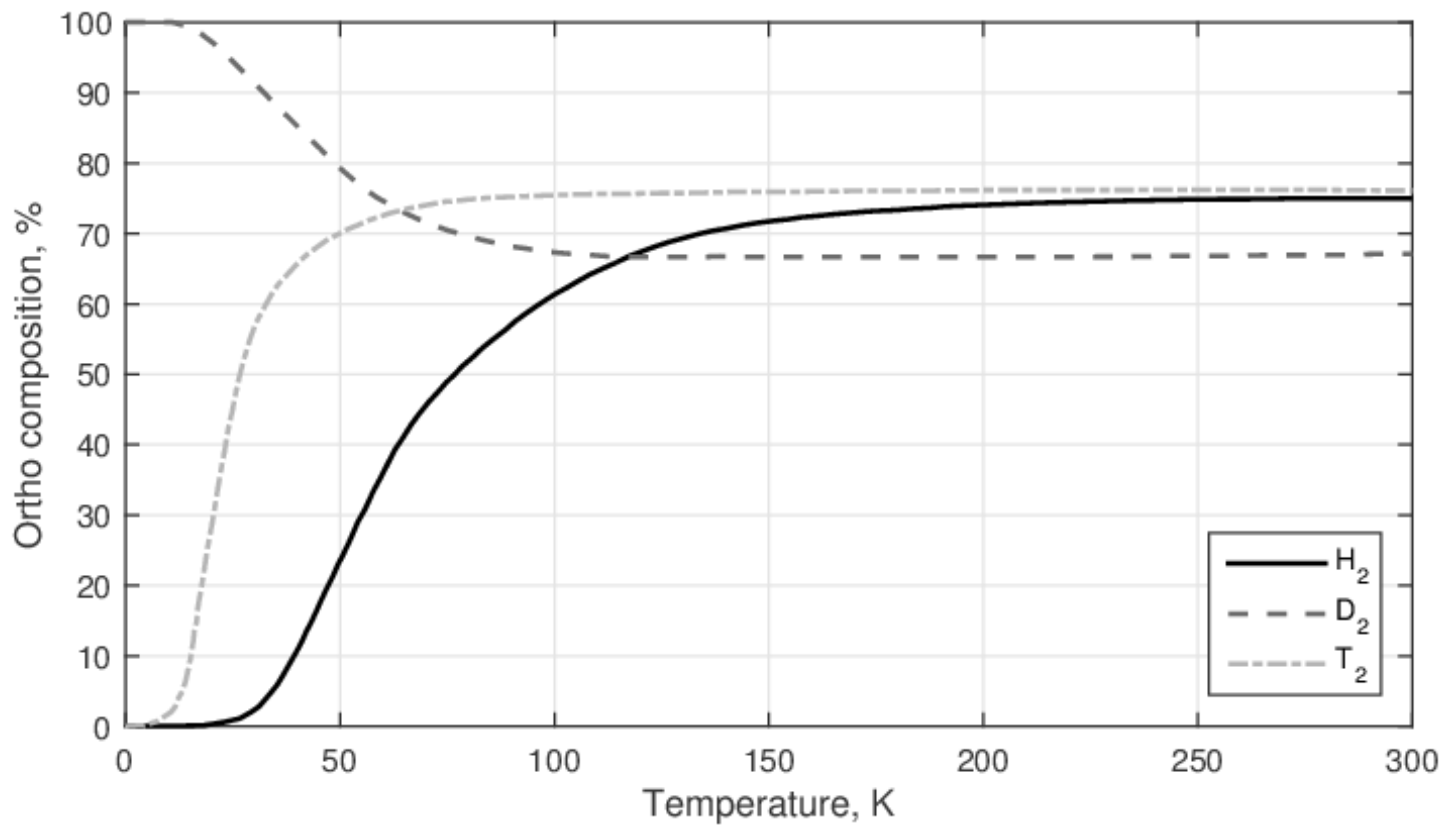

Figure 19.4. Ortho-para composition for $\mathrm{H}_{2}, \mathrm{D}_{2}$ and $\mathrm{T}_{2}$ at equilibrium from $\mathrm{O}$ to $300 \mathrm{~K}$. However, the orthopara conversion is a very slow process. Therefore, the equilibrium composition at room temperature, called normal composition, is of interest for the cryogenic distillation of hydrogen isotope because it is fast process compared to that conversion (redrawn from [12, Fig. 6]).

Table 19.2. Fixed points for (most of) the isotopic forms and ortho/para modifications of molecular hydrogen (elaborated from [23, Tab.11-1]).

\begin{tabular}{|c|c|c|c|c|c|}
\hline $\begin{array}{l}\text { Form and } \\
\text { modification }\end{array}$ & $\begin{array}{c}\text { Triple point } \\
\text { Temperature }\end{array}$ & $\begin{array}{c}\text { Triple point } \\
\text { pressure }\end{array}$ & $\begin{array}{c}\text { Normal Boiling } \\
\text { Point }\end{array}$ & $\begin{array}{l}\text { Critical point } \\
\text { temperature }\end{array}$ & $\begin{array}{c}\text { Critical point } \\
\text { pressure }\end{array}$ \\
\hline & $\mathbf{K}$ & bar & $\mathrm{K}$ & $\mathbf{K}$ & bar \\
\hline \multicolumn{6}{|c|}{ Homonuclear diprotium } \\
\hline $\mathrm{oH}_{2}$ & 14.05 & 0.0735 & 20.454 & NA & NA \\
\hline$p \mathrm{H}_{2}$ or $e-\mathrm{H}_{2}$ & 13.803 & 0.07042 & 20.268 & 32.976 & 12.928 \\
\hline$n-H_{2}$ & 13.957 & 0.07205 & 20.39 & 33.19 & 13.15 \\
\hline \multicolumn{6}{|c|}{ Homonuclear dideuterium } \\
\hline$o D_{2}$ or $e-D_{2}$ & 18.691 & 0.1713 & 23.63 & 38.262 & 16.450 \\
\hline$p D_{2}$ & 18.78 & 0.1713 & 23.66 & NA & NA \\
\hline$n-D_{2}$ & 18.71 & 0.1713 & 23.66 & 38.34 & 16.650 \\
\hline \multicolumn{6}{|c|}{ Ditritium } \\
\hline$T_{2}$ & 20.62 & 0.2160 & 25.04 & 40.44 & 18.502 \\
\hline \multicolumn{6}{|c|}{ Heteronuclear diatomic hydrogen } \\
\hline$H D$ & 16.60 & 0.124 & 22.143 & 35.908 & 14.84 \\
\hline$H T$ & 17.62 & 0.1460 & 22.92 & 37.13 & 15.70 \\
\hline DT & 19.71 & 0.1942 & 24.38 & 39.42 & 17.70 \\
\hline
\end{tabular}




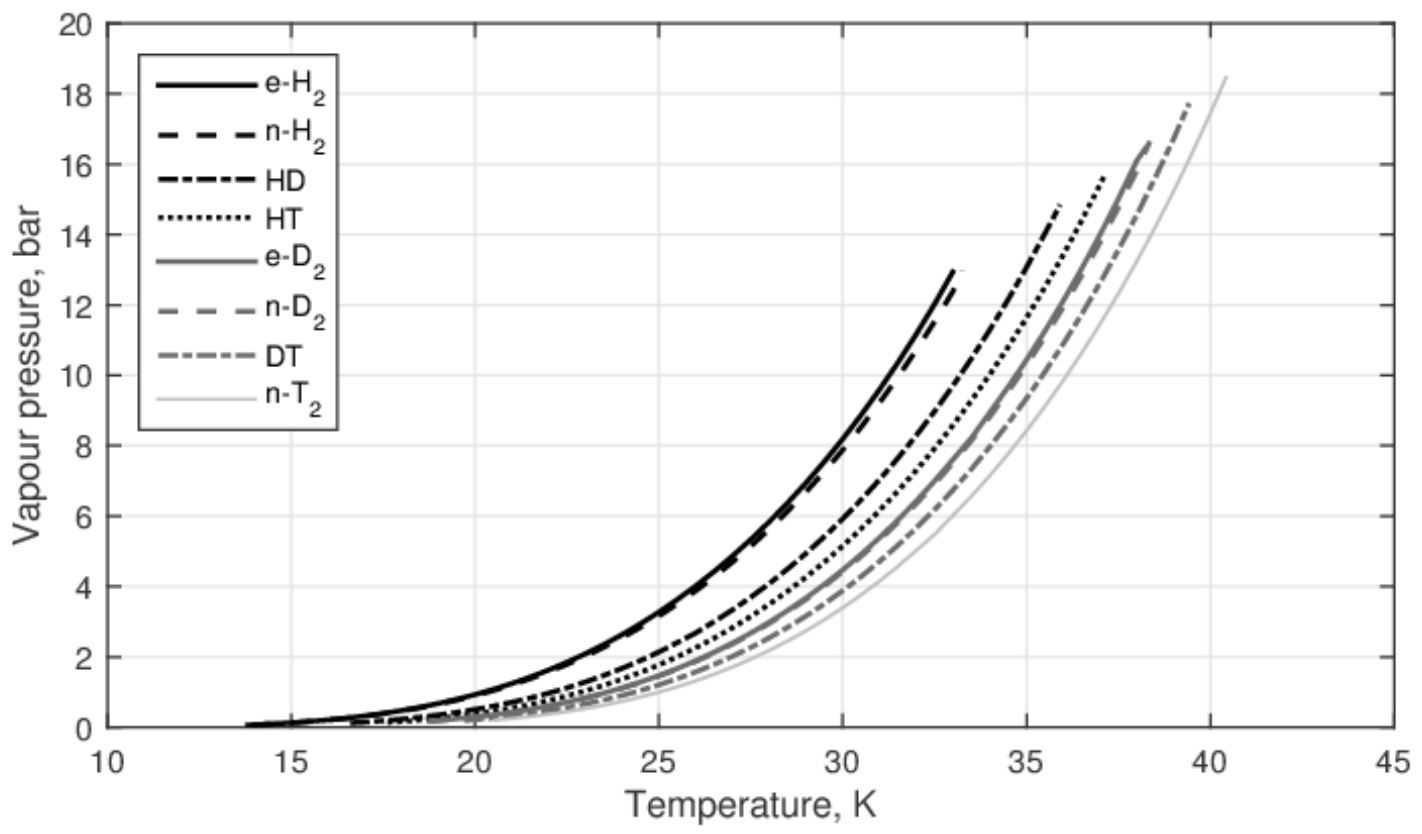

Figure 19.5. Vapour pressures for (most of) the isotopic forms and ortho/para modifications of molecular hydrogen from triple point to critical point (elaborated and drawn from [23, Tab. 10-2]). 


\subsection{Basics of Cryogenic Distillation}

Distillation is a process for separating two or more components from a mixture based on their different vapour pressures. It is adopted commonly in industrial applications because of the advantages of achieving high separation degrees and of processing large quantities of fluids. Green and Perry [30] as well as McCabe et al. [31] describe the general process in two well-known textbook, while Andreev et al. [6] focus on the process for separating biogenic isotopes. Flynn et al. [32] as well as Benedict et al. [33] illustrate specifically the deuterium distillation. Lastly, Busigin and Sood [7] as well as Cristescu et al. [34] specifically the tritium separation. Distillation requires the coexistence of liquid and vapour phases, a condition that occurs exclusively at cryogenic conditions for molecular hydrogen. Cryogenics means literally the production of icy cold from ancient Greek and it is used today as synonym for temperatures lower than, indicatively, $-150^{\circ} \mathrm{C}$ (123 K). As seen in Section 19.2.3, triple and critical temperatures of the various isotopic forms and ortho/para modifications of molecular hydrogen fall in the range $10-40 \mathrm{~K}$. This section describes first the fundamental working principle of the distillation process and outlines after its application to the hydrogen mixtures.

\subsubsection{Fundamental Working Principle}

In general terms, the separation operation of components from their mixture is achieved by the creation of two or more adjacent zones that differ gradually in temperature, pressure, composition, and/or phase state [30]. Distillation is a separation operation exploiting the physical equilibria between the vapour and the liquid phase within each zone. It is accomplished by vertical columns in which these zones are created by stacked trays or by packings. The feed to be separated is introduced at one or more points along the column height. Because of the difference in density between vapour and liquid phases, liquid runs down the column, cascading from zone to zone, while vapour flows up the column, contacting liquid at each zone. Liquid reaching the bottom of the column is partially vaporized by a heating mean to provide boil-up, which flows up the column. The remainder of the bottom liquid is withdrawn as bottom product. Vapour reaching the top of the column is condensed by a cooling mean. Part of this liquid is returned to the column as 
reflux, which runs down the column. The remainder of the liquid is withdrawn as overhead product. In some cases, only part of the vapour is condensed so that the overhead product is a vapour. This overall flow pattern in a distillation column provides countercurrent contacting of vapour and liquid streams at all zones along the column, while the heating of the bottom and the cooling of the top support a temperature gradient. The lighter components tend to concentrate in the vapour phase at the lower temperatures, while the heavier components in the liquid phase at higher temperatures. Lighter components are those characterized by higher vapour pressures, hence higher volatility and lower boiling points; vice versa, heavier by lower vapour pressures, hence lower volatility and higher boiling points. Therefore, the overall result is a vapour phase that becomes richer in lighter components as it flows up the column and a liquid phase that becomes richer in heavier components as it runs down.

A distillation column is assessed by its separation factor, which may be defined conceptually as the ratio of the concentration of the desired component in the product where it concentrates (either bottom or overhead) with respect to its concentration in the other product. If the separation factor of a single column does not allow achieving the targeted purity of the desired component, more columns can be arranged in a proper sequence. Each column is referred to as a distillation stage.

\subsubsection{Application to Hydrogen Isotopes}

In hydrogen distillation, the desired components are typically the heavier isotopes, deuterium and tritium, which are characterized by lower vapour pressures than protium, as reported in Section 19.2.3. Moreover, typical targeted purities require three or four distillation stages. Hence, they concentrate progressively in the liquid bottom products, while protium concentrates in the gaseous overhead products.

Furthermore, hydrogen mixtures do not contain only homonuclear diatomic molecules, $H_{2}, D_{2}, T_{2}$, but primarily heteronuclear ones, $H D, H T$ and $D T$. The isotope exchange reactions describe the equilibrium among heteronuclear and homonuclear molecules (Section 19.2.3). The equilibrium is reached slowly 
unless catalysed, but shifts favourably towards the homonuclear molecules at lower temperatures. Hence, catalytic reactors (also said catalytic equilibrators) are placed generally between the last two distillation stages to promote the formation of $H_{2}, D_{2}$ and $T_{2}$ and ease the separation of the isotopes, $D$ and $T$, in their homonuclear diatomic molecules.

Figure 19.6 depicts the conceptual design of deuterium separation as proposed by Flynn et al. in 1960 [32]. Since deuterium occurs in the form of $H D$ rather than $D_{2}$, as recalled above, the first and second distillation stages aim at concentrating $H D$ in their bottom products (respectively 3 per cent and 95 per cent). Then, the bottom product of the second column is enriched in $D_{2}$ by a catalytic reactor. A third distillation stage allows for a high purity $D_{2}$ in a liquid phase. (In this design, the separated deuterium is utilized along with oxygen to produce heavy water.) A similar concept could be implemented for the separation of tritium.

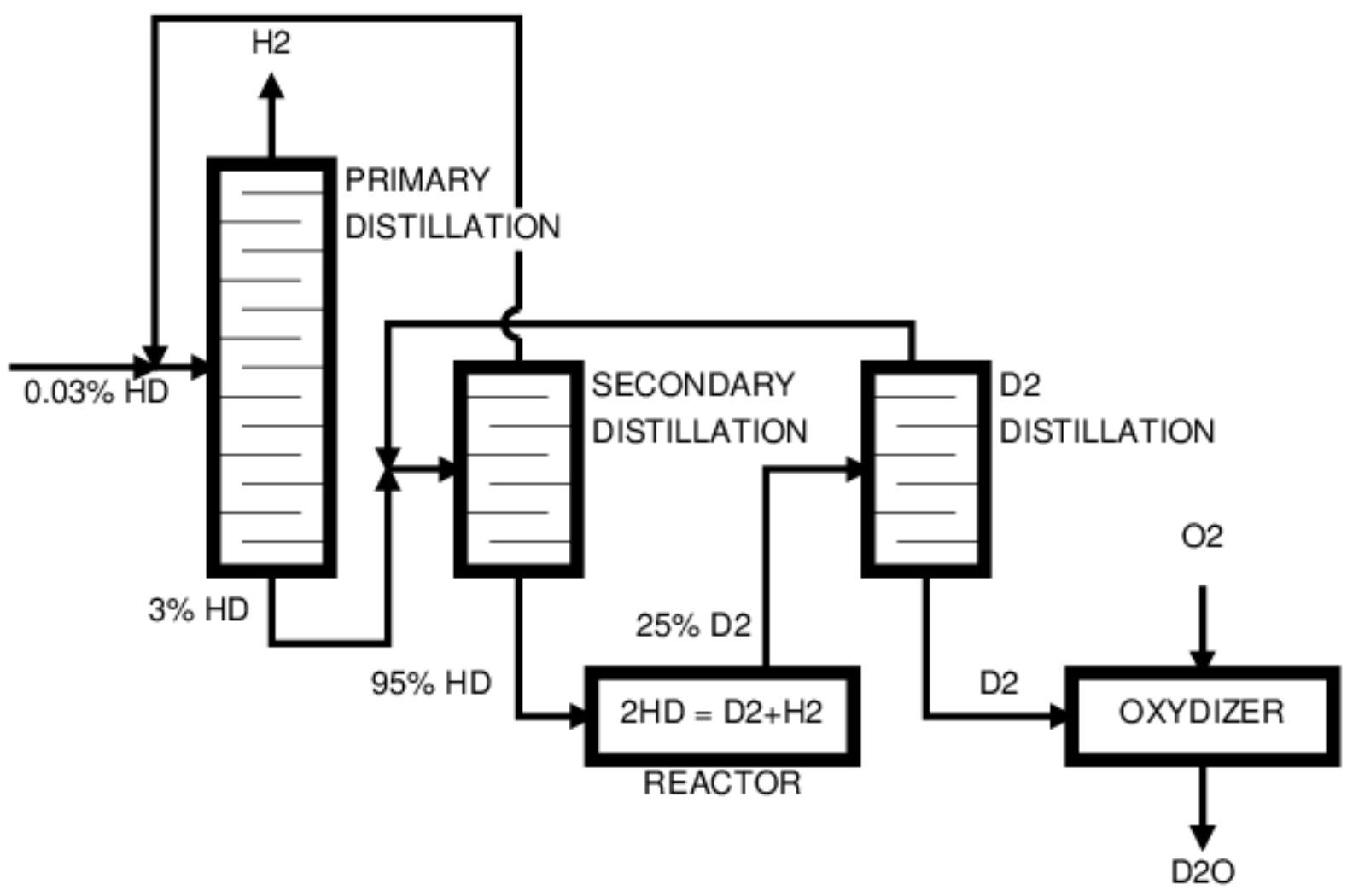

Figure 19.6. Process flow diagram of deuterium separation from a $\mathrm{H}_{2}, H D, D_{2}$ mixture by way of a threestage distillation and one catalytic reactor the promotes the formation of the homonuclear diatomic molecules at low temperature (redrawn from Flynn et al. [32]). 


\subsection{Basics of Cryogenic Liquefaction}

Cryogenic liquefaction is the process of turning a gaseous components at atmospheric conditions into a liquid at atmospheric pressure yet cryogenic temperature. Cryogenic liquefaction applies to the so-called permanent gases: helium, hydrogen, neon, nitrogen and oxygen (as well as air in a more general sense). The following sections outline briefly the fundamental cooling effects, the fundamental liquefaction cycles and the current industrial technology. The textbooks by Barron [35] or by Flynn [36] shall be referred to for the general topic of cryogenic systems, while the review by Valenti [37] for the specific topic of hydrogen liquefaction.

\subsubsection{Fundamental Cooling Effects}

Cryogenic liquefiers are based on the thermodynamic concept that the cooling effect is obtained by expanding adiabatically a fluid from a proper initial condition. The adiabatic expansion can be executed either with or without extracting energy from the fluid being expanded. The expansion without energy extraction, which is an isenthalpic process, is realized by a throttling valve; the expansion with energy extraction, which is ideally an isentropic process, by an expanding fluid machine. Because liquefiers are based on the expansion of a fluid, they require a compression process to complete the cycle. This compression is executed at ambient temperature and, commonly, in an intercooled manner. Thus, there are two methods for achieving a cooling effect within a liquefaction plant:

- throttling through a valve, which is described from a thermodynamic point of view by the JouleThomson coefficient and the inversion curve;

- expanding via a fluid machine.

\subsubsection{Fundamental Liquefaction Cycles}

The most fundamental liquefaction scheme is the (simple or single-pressure) Linde-Hampson cycle, illustrated in Figure 19.7.a, which employs exclusively a throttling valve to achieve the cooling effect. The performance of the plant, which is however never high, can be improved by the splitting of the throttling over two pressure levels. This new scheme is named dual-pressure Linde-Hampson cycle and depicted by 
Figure 19.7.b. In case the fluid to be liquefied has an inversion curve below the ambient temperature for any pressure, like hydrogen, the process requires a precooling system, which cools the stream prior to the recuperative heat exchanger and to the throttling valve (Figure 19.7.c).

The performance of the liquefier can be increased remarkably by the adoption of an expanding fluid machine. The fundamental scheme comprising the expander is the Claude cycle (Figure 19.8.a). Likewise the Linde-Hampson, the Claude cycle can operate over an additional pressure level. In this case, the throttling valve works between maximum and minimum pressures while the machine between mid and minimum (Figure 19.8.b). Moreover, the Claude cycle can adopt a precooling system, despite it is not strictly necessarily also for those fluids that, like hydrogen, have a low inversion curve (Figure 19.8.c).

Furthermore, there are few other fundamental cycles derived from the Claude one as well as additional liquefaction cycles operating with working fluids different from hydrogen. However, these cycles are not reported here because not so pertinent to the topic of current hydrogen liquefaction and distillation. In any of these cycles, the stream of hydrogen to be liquefied is always at a pressure higher than its critical pressure. At supercritical pressure, indeed, there is not a phase change within any of the heat exchangers, which would lead to small temperature variations upon large energy transfers. In contrast, a subcritical (pure) fluid would require extracting the condensation energy at a constant temperature, which is an adverse situation for achieving high effectiveness of the heat exchangers (or low entropy generation from a second-law perspective). 

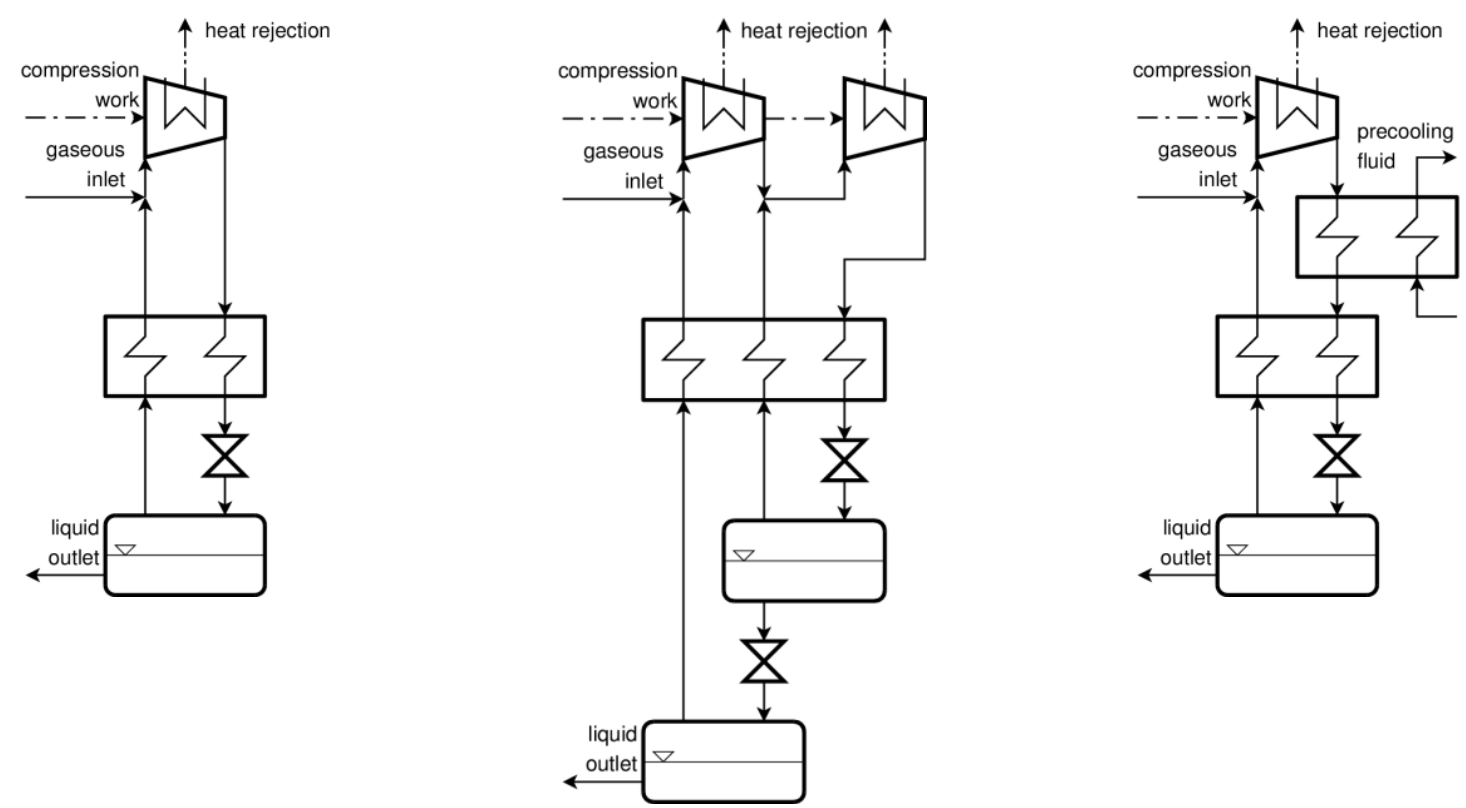

a. simple or single-pressure

b. dual-pressure

c. single-pressure with precooling

Figure 19.7. Linde-Hampson cycle in the simple or single-pressure configuration (left), dual-pressure (centre) and single-pressure with precooling (right). In these cycles, the processed fluid is also the working fluid.

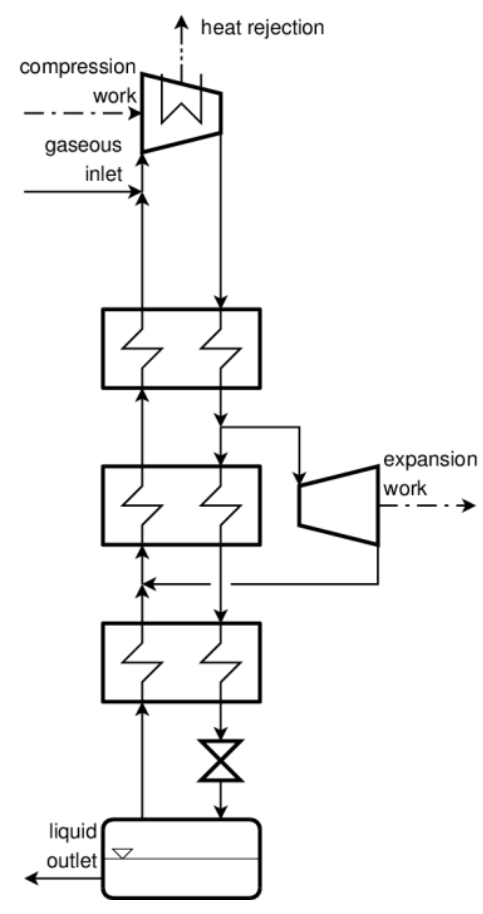

a. simple or single-pressure

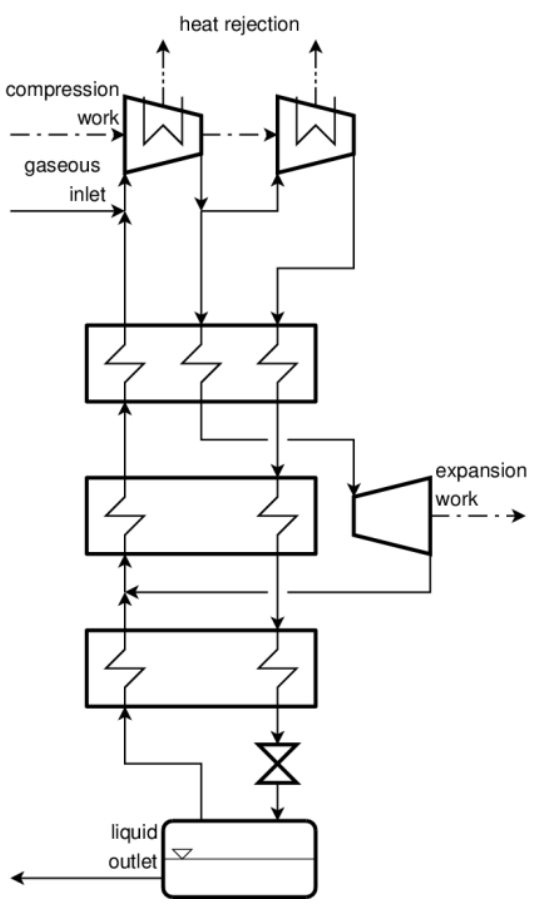

b. dual-pressure

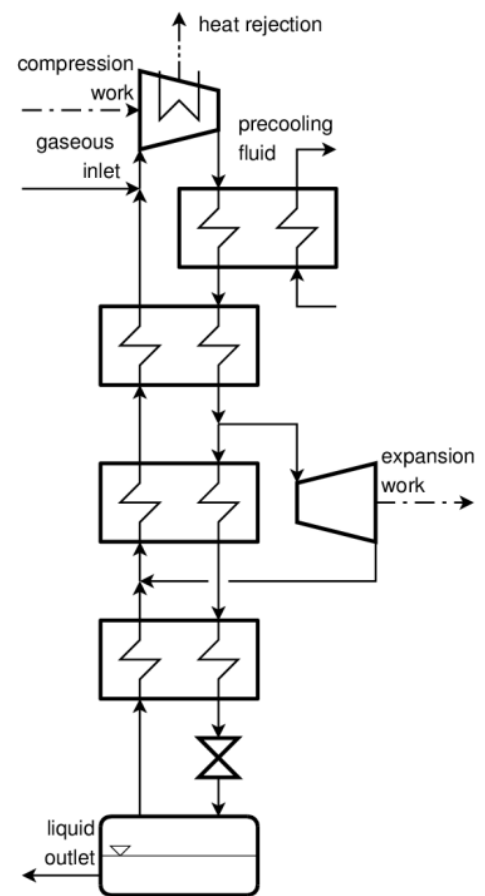

c. single-pressure with precooling

Figure 19.8. Claude cycle in the simple or single-pressure configuration (left), dual-pressure (centre) and single-pressure with precooling (right). In these cycles, the processed fluid is also the working fluid. 


\subsubsection{Current Hydrogen Liquefaction Plants}

A hydrogen liquefier may be classified as small if its capacity is up to $0.5 \mathrm{t} \mathrm{day}^{-1}$ and large if greater than $5.0 \mathrm{t} \mathrm{day}^{-1}$, while the World hydrogen liquefaction capacity is estimated to fall within the range $300-$ 350 t day $^{-1}$. Small- and large-scale hydrogen liquefiers do not differ just in the capacity but also in the manner by which liquefaction is accomplished. Small-scale hydrogen liquefaction is realized by cryogenic refrigerators, which are systems operating with a refrigerant in a closed-loop thermodynamic cycle that cools and liquefies the hydrogen stream. In the case of hydrogen, the adopted refrigerant is helium. In contrast, large-scale liquefaction is accomplished by open-loop thermodynamic cycles in which hydrogen is both the processed fluid and the working fluid. This distinction is only technological because from a theoretical perspective closed-loop refrigerators can be resized to large scales, as well as open-loop plants downsized. In addition, for very small hydrogen liquefiers, magnetic refrigerators may be employed.

Large-scale hydrogen liquefiers must employ a catalytic ortho-to-parahydrogen conversion reactors if the liquid has to be stored over time because, as seen in Section 19.2.3, the reaction is highly exothermic and otherwise very slow. The reaction is so exothermic that the associated enthalpy of conversion is greater than the enthalpy of vaporization at storage tank pressure. In brief, if orthohydrogen were not converted during liquefaction, the conversion would occur slowly in the storage tank and it would release an amount of energy large enough to vaporize the entire content of that tank over a timespan of about two months.

Today's large-scale hydrogen liquefiers are based on the modification of the precooled Claude cycle shown in Figure 19.9. Precooling is obtained by a dedicated refrigeration cycle or by liquid nitrogen. Catalytic conversion of orthohydrogen to parahydrogen can be executed in a batch mode or in a continuous mode. If in batch mode, reactors can be either adiabatic or isothermal. Isothermal reactors are immerged in liquid nitrogen or in liquid hydrogen baths. If in continuous mode, the catalyst is placed within the heat exchangers. From a point of view of liquefaction work requirement, continuous conversion is definitely more efficient. Typically, hydrogen liquefiers are design to produce a liquid with a parahydrogen content 
greater than 95\%. For reference, Bracha et al. give a accurate description of a recent hydrogen liquefier that, despite not any more in operation, is still representative for the current technology.

The hydrogen liquefaction work depends strongly on inlet conditions (pressure and temperature), outlet conditions (saturation pressure and parahydrogen content), and ambient temperature. For an inlet at 1 bar and $288 \mathrm{~K}$, an outlet of saturated liquid at 1 bar and equilibrium composition, and an ambient at $288 \mathrm{~K}$, the ideal liquefaction work is $13.6 \mathrm{MJ} \mathrm{kg}^{-1}\left(3.78 \mathrm{kWh} \mathrm{kg}^{-1}\right)$. If the inlet pressure is 20 bar instead of $1 \mathrm{bar}$, as typical for a number of hydrogen production processes, the ideal liquefaction work is $9.97 \mathrm{MJ} \mathrm{kg}^{-1}$ $\left(2.77 \mathrm{kWh} \mathrm{kg}^{-1}\right)$. The real liquefaction work of current large-scale liquefiers is in the range $30-45 \mathrm{MJ} \mathrm{kg}^{-1}$ (about 8-12 $\mathrm{kWh} \mathrm{kg}^{-1}$ ), for an inlet at about 20 bar and a parahydrogen content of at least of $95 \%$.

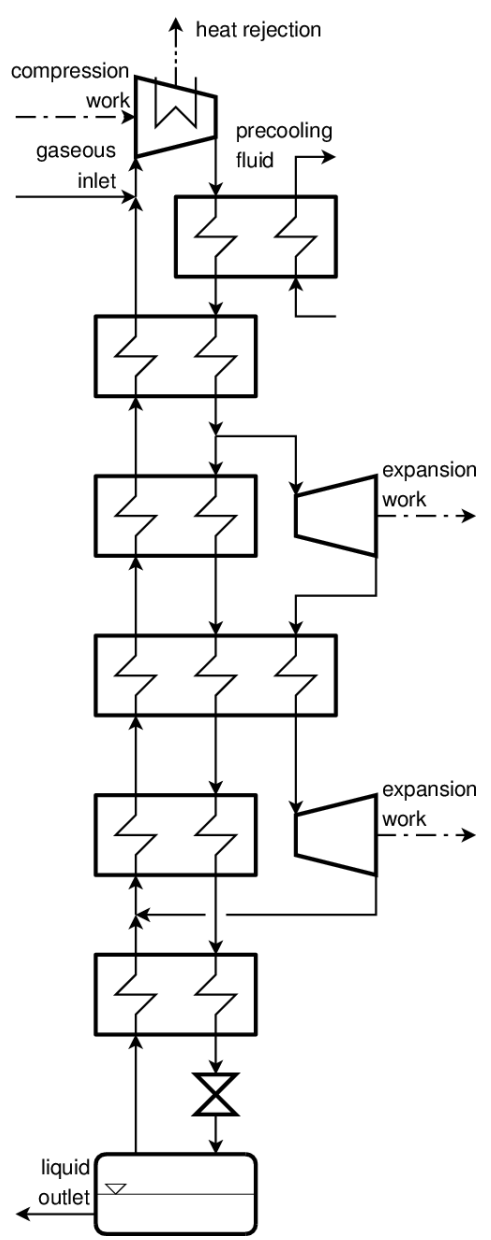

Figure 19.9. Modern large-scale hydrogen liquefiers are based on modifications of the fundamental Claude cycle and employ catalytic orthohydrogen to parahydrogen conversion reactors, either in a batch mode or in continuous mode. 


\subsection{Reference Plants}

Despite being adapt for industrial-size applications, the number of cryogenic distillation plants constructed for deuterium and tritium separation is small due to the limited market of these two isotopes. The following two sections provide an example of a separation plant for deuterium and one for tritium.

\subsubsection{Deuterium Separation}

A cryogenic distillation facility for the separation of deuterium from a hydrogen stream was erected in Hoechst, Germany, during the late 1960s [39]. The scope of the facility, that was operated for a limited number of years, was producing heavy water for fission nuclear reactors. The facility comprised two distillation sections:

- the first distillation section concentrated $H D$ at a purity of 95 per cent, because molecular hydrogen occurs naturally in $H_{2}$ and $H D$ forms rather than $D_{2}$ (there are approximately $10^{4}$ molecules of $H D$ for 1 molecule of $D_{2}$ ),

- the second distillation section promotes catalytically the isotope exchange reaction to yield $\mathrm{H}_{2}$ and $D_{2}$ from $H D$, and then it separates $D_{2}$ at a purity of 99.8 per cent.

Figure 19.10 depicts a schematic process flow diagram of the facility. The first sections includes two columns, the first one of which concentrates $H D$ at the intermediate purity of 5 per cent; the second section a single column. Both sections operate in the $20-25 \mathrm{~K}$ range, which is reached by way of a singlepressure Linde-Hampson cycle with liquid nitrogen precooling at around $80 \mathrm{~K}$. Overall, the distillation facility enriched deuterium from just $150 \mathrm{ppm}$ in the hydrogen inlet stream to a purity 99.8 per cent in the deuterium outlet stream. In addition, 95 per cent of the deuterium entering the distillation facility was separated, while the total annual production was $1080 \mathrm{~m}^{3}$ (at standard conditions). Shortly later, Linde built a similar distillation plant in Nangal, India, that was in service until recent years. 


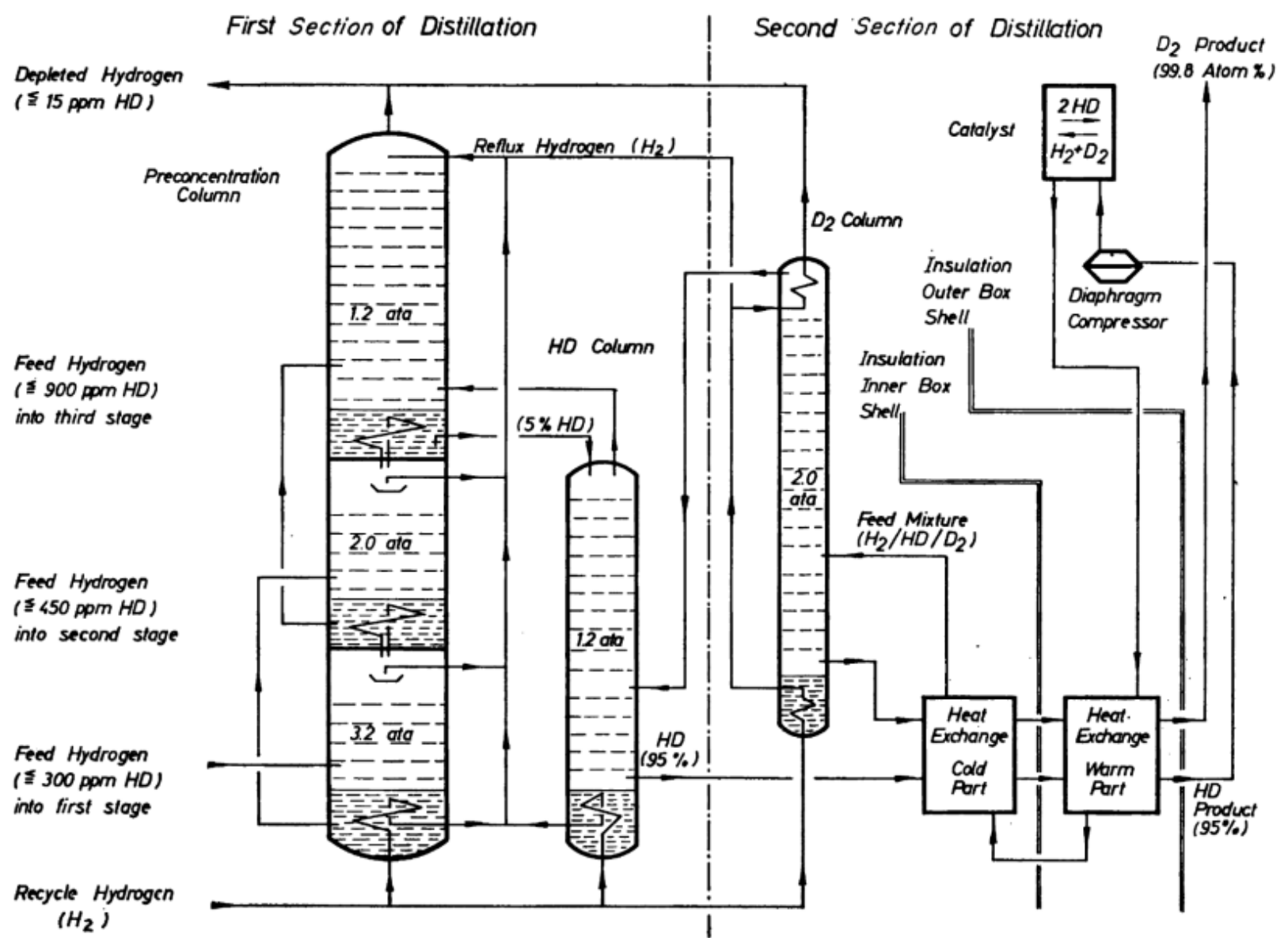

Figure 19.10. Process flow diagram of the Linde cryogenic distillation plant erected in late 1960s (by Scott et al. [39]).

\subsubsection{Tritium Separation}

A tritium removal facility for the detritiation of the heavy water from nuclear fission reactors was erected in Darlington, Canada, during the late 1980 s $[7,40]$. The scope of the facility, still in operation, is reducing the radioactivity environmental emissions and worker radiation doses caused by heavy water leakages from the equipment of the nuclear power plant. The facility comprises two sections:

- a vapour phase catalytic exchange section, which extracts tritium from the irradiated water into a deuterium-rich stream by way of eight stages,

- a cryogenic distillation section, which concentrates tritium by way of four columns with several hundred theoretical stages and a catalytic equilibrator. 
Figure 19.11 depicts a schematic process flow diagram of the facility. The four columns are arranged in a simple cascade such that the (liquid) bottom product of each column, richer in tritium than that column feed, enters the next column, while its (vapour) overhead product, richer in the lighter isotopes, enters the previous column. The overhead product of the fourth and last column, prior to entering the third column, flows into a catalytic equilibrator, which is a catalysed reactor that favours the isotopic exchange of heteronuclear molecules to homonuclear ones (Section 19.2.3) and, hence, promotes the formation of $T_{2}$ to be separated. Overall, the facility enriches tritium from just parts per millions in the heavy water inlet stream to a purity of $99.9 \%$ per cent in the tritium outlet stream, achieving a remarkable separation factor. Ultimately, tritium is stored as a metal hydride.

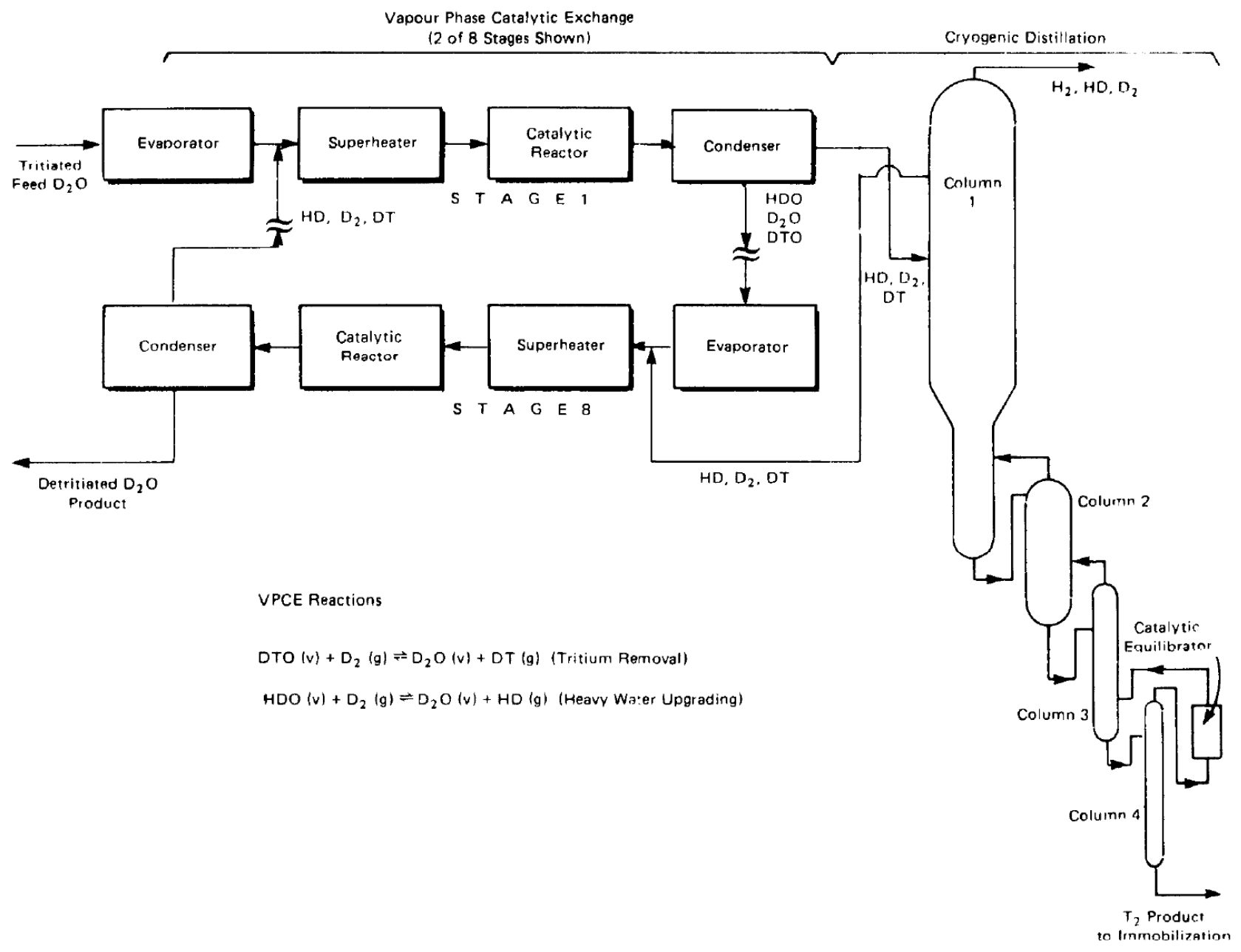

Figure 19.11. Process flow diagram of the Darlington Tritium Removal Facility erected in late 1980s (by Busigin and Sood $[7,40])$. 


\subsection{Further Reading}

The interested reader may refer first to the two well-known textbooks by Barron [35] and Flynn [36]. In addition, the reader can locate the other reports and articles cited in this work. More in general, detailed information may be derived from two reference journals of the sector: (i) the International Journal of Hydrogen Energy and (ii) Cryogenics. Furthermore, the proceedings of Romanian conference Progress in Cryogenics and Isotopes Separation may be also valuable sources of data, as well as the websites of IUPAC, CIAAW, NIST, ITER and the International Atomic Energy Agency. 


\subsection{Conclusions}

In most hydrogen processes, a distinction among its isotopes is unnecessary being the concentration of protium larger by far than that of deuterium and tritium. However, these two heavier isotopes have peculiar applications, such as those related with nuclear fission as well as fusion reactors, that place a great attention upon them. There exists a number of techniques for isotope separation and, among them, cryogenic distillation has been proved a mature process for the industrial-scale processing of hydrogen. Two reference plants were built in the 1960s and 1980s, respectively, during the years of growing interest for nuclear energy in the civil and military sectors. Today, such interest has decreased, but it is expected to increase more than ever before in view of the future nuclear fusion reactors. 


\section{Nomenclature}

Acronyms

$\begin{array}{ll}\text { CIAAW } & \text { Commission on Isotopic Abundances and Atomic Weights } \\ \text { ITER } & \text { International Thermonuclear Experimental Reactor } \\ \text { IUPAC } & \text { International Union of Pure and Applied Chemistry } \\ \text { NASA } & \text { United States National Aeronautics and Space Administration } \\ \text { NBS } & \text { United States National Bureau of Standards } \\ \text { NIST } & \text { United States National Institute of Standards and Technology }\end{array}$

Symbols

$\begin{array}{ll}A & \text { Mass (or nucleon) number } \\ Z & \text { Atomic (or proton) number } \\ e & \text { Elementary (or proton) charge }\end{array}$




\section{Reference List}

$1 \quad$ Hawking S., Mlodinow L. A briefer history of time. Bantam Press. 2005.

2 Ridgen J. Hydrogen: The essential element. Harvard University Press. 2003.

3 Murray R.L., Nuclear Energy: An Introduction to the Concepts, Systems, and Applications of Nuclear Processes. Butterworth-Heinemann. 2014. Horton C.W., Benkadda S. ITER Physics. World Scientific New Jersey. 2015.

$5 \quad$ http://www.iter.org Andreev B.M., Magomedbekov E.P., Raitman A.A., Pozenkevich M.B., Sakharovsky Yu.A., Khoroshilov A.V. Separation of Isotopes of Biogenic Elements in Two-phase Systems. Elsevier. 2006. Busigin A., Sood S.K. 'Optimization of Darlington Tritium Removal Facility Performance: Effects of key process variables'. Nuclear Journal of Canada. 1987;1(4), 368-371. Ahn D.H., Lee H.S., Chung H.S., Song M.-J., Son S.-H. 'Optimum design of the Wolsong Tritium Removal Facility'. Journal of the Korean Nuclear Society. 1996;28(4), 415-423.

9 Bartlit J.R., Sherman R.H., Stutz R.A., Denton W.H. 'Hydrogen isotope distillation for fusion power reactors'. Cryogenics. 1979;19(5), 275-279. doi:10.1016/0011-2275(79)90142-5

10 Busigin A, Sood S.K., Kveton O.K., Dinner P.J., Murdoch D.K., Leger D. 'ITER hydrogen isotope separation system conceptual design description'. Fusion Engineering and Design. 1990;13(1), 77-89. doi:10.1016/0920-3796(90)90035-5

11 International Union of Pure and Applied Chemistry (IUPAC). Golden Book. 2014

12 Kakiuchi M. Hydrogen: Inorganic Chemistry. In Encyclopaedia of Inorganic and Bioinorganic Chemistry. John Wiley \& Sons, Online. 2011. doi:10.1002/9781119951438.eibc0086

13 Deuterium. In Encyclopaedia of Inorganic and Bioinorganic Chemistry. John Wiley \& Sons, Online. 2011. doi:10.1002/9781119951438.eibd0219

14 Galeriu D, Melintescu A. Tritium: radionuclide. In Encyclopaedia of Inorganic and Bioinorganic Chemistry. John Wiley \& Sons, Online. 2011. doi:10.1002/9781119951438.eibc0413 
15 Bunnett J.F., Jones R.A.Y. 'Names for hydrogen atoms, ions, and groups, and for reaction involving them'. Pure and Applied Chemistry. 1988; 60(7), 1115-1116. doi:10.1351/pac198860071115

16 Korsheninnikov A.A., Nikolskii E.Yu., Kuzmin E.A., Ozawa A., Morimoto K., Tokanai F., et al. 'Experimental Evidence for the Existence of ${ }^{7} \mathrm{H}$ and for a Specific Structure of ${ }^{8} \mathrm{He}^{\prime}$. Physical Review Letters. 2003;90(8), 082501-1-4. doi:10.1103/PhysRevLett.90.082501

17 Berglund M., Wieser M.E. 'Isotopic composition of the elements 2009 (IUPAC Technical Report)'. Pure and Applied Chemistry. 2011;83(2), 397-410. doi:10.1351/PAC-REP-10-06-02

18 Tien, C.L., Lienhard, J.H. Statistical thermodynamic. Revised printing, Hemisphere Publishing. 1988.

19 Woolley H.W., Scott R.B., and Brickedde F.G. 'Compilation of thermal properties of hydrogen in its various isotopic and ortho-para modifications'. Research paper RP1932, Journal of Research of the National Bureau of Standards. 1948;41(5), 379-475.

20 Hoge H.J., Arnold R.D. 'Vapor pressures of hydrogen, deuterium, and hydrogen deuteride and dewpoint pressures of their mixtures'. Research paper 2228, Journal of Research of the National Bureau of Standards. 1951;47(2), 63-74.

21 Hoge H.J., Arnold R.D. 'Critical temperatures, pressures, and volumes of hydrogen, deuterium, and hydrogen deuteride'. Research paper 2229, Journal of Research of the National Bureau of Standards. $1951 ; 47(2), 75-79$.

22 Haar L., Friedman A.S., Beckett C.W. Ideal gas thermodynamic functions and isotope exchange functions for the diatomic hydrides, deuterides, and tritides. United States National Bureau of Standards Monograph 20, 1961.

23 Roder H.M., Childs G.E., McCarty R.D., Angerhofer P.E. Survey of the properties of the hydrogen isotopes below their critical temperatures. United States National Bureau of Standards Technical Note 641, 1973.

24 McCarty R. D., Hord J., Roder H. M. Selected properties of hydrogen (Engineering design data), National Bureau of Standards Monograph 168, 1981. 
25 Jacobsen R. T., Leachman J. W., Penoncello S. G., Lemmon E. W. 'Current Status of Thermodynamic Properties of Hydrogen'. International Journal of Thermophysics. 2007;28(3), 758-772.

doi:10.1007/s10765-007-0226-7

26 Leachman, J. W., Jacobsen R. T., Penoncello S. G., Huber M. L. 'Current Status of Transport Properties of Hydrogen'. International Journal of Thermophysics. 2007;28(3), 773-795. doi:10.1007/s10765-007$\underline{0229-4}$

27 Leachman J. W., Jacobsen R. T., Penoncello S. G., Lemmon E. W. 'Fundamental Equations of State for Parahydrogen, Normal Hydrogen, and Orthohydrogen'. Journal of Physical and Chemical Reference Data. 2009;38(3), 721-748. doi:10.1063/1.3160306

28 Richardson I.A., Leachman J.W. 'Thermodynamic properties status of deuterium and tritium' AIP Conference Proceedings. 2012;1434, 1841-1848. doi:10.1063/1.4707121

29 Richardons I.A., Leachman J.W., Lemmon E.W. 'Fundamental Equation of State for Deuterium' Journal of Physical and Chemical Reference Data. 2014;43(1), 013103-1-013103-13.

doi:10.1063/1.4864752

30 Green D., Perry R. Perry's chemical engineer's handbook. Eighth edition. McGraw-Hill Education. 2007.

31 McCabe W., Smith J.C., Harriott P. Unit operations of chemical engineering. Seventh edition. McGraw-Hill Education. 2004.

32 Flynn T.M., Weitzel D.H., Timmerhaus K.D., Vander Arend P.C., Draper J.W. 'Distillation of hydrogendeuterium mixtures' Advances in Cryogenic Engineering. 1960;2, 39-44. doi:10.1007/978-1-4684$\underline{3102-56}$

33 Benedict M., Pigford T.H., Levi H.W. Nuclear chemical engineering. Second edition. McGraw-Hill. 1981.

34 Cristescu I., Cristescu I. Peculea M. Studies about the separation of molecular species of hydrogen's isotopes by cryogenic distillation in a plant for heavy water detritiation. In Hydrogen Power: 
Theoretical and Engineering Solutions. Kluwer Academic Publishers. 1998. doi:10.1007/978-94-0159054-9 73.

35 Barron R. F. Cryogenic systems. Second Ed. New York, Oxford University Press. 1985.

36 Flynn T. M. Cryogenic engineering. Second Ed. New York, Marcel Dekker. 2005.

37 Valenti G. Hydrogen liquefaction and liquid hydrogen storage. In Compendium of Hydrogen EnergyVolume 2: Hydrogen Storage, Distribution and Infrastructure. Woodhead Publishing. 2015.

38 Bracha M., Lorenz G., Patzelt A., Wanner M. (1994) 'Large-scale hydrogen liquefaction in Germany' International Journal of Hydrogen Energy. 1994;19(1), 53-59. doi:10.1016/0360-3199(94)90177-5

39 Scott. R.B., Denton W.H., Nicholls C.M. Technology and Uses of Liquid Hydrogen. Pergamon Press. 1964.

40 Busigin A., Sepa T.R., Sood S.K. 'Flosheet: Microcomputerized Flowsheeting / Simulation Program for Simulating Hydrogen Isotope Separation Processes'. Separation Science and Technology. 1987;22(23), 557-579. doi:10.1080/01496398708068969 


\section{Acknowledgements}

The author is very grateful to prof. Hans Quack for sharing his knowledge and to Michela Capoccia as well as Andrea Seghezzi, from SAPIO Produzione Idrogeno Ossigeno S.r.l., for exchanging information. 